\title{
O seminário como instrumento de avaliação processual e prática reflexiva na formação inicial de professores
}

The seminar as a procedural evaluation and reflective practice instrument for initial teacher education

\author{
Marcos Bispo dos Santos
}

Universidade do Estado da Bahia - UEBA

DOI: https://doi.org/10.5902/2176148539577

\begin{abstract}
Resumo: Este texto apresenta reflexões sobre uma experiência pedagógica de produção do gênero seminário, com o objetivo de analisar o papel da oralidade em múltiplas dimensões da atividade docente, entre as quais serão destacadas a reflexão sobre os saberes e crenças dos professores e o desenvolvimento de habilidades de comunicação. A metodologia adotada se insere no contexto das discussões sobre saberes e profissionalização docentes situadas no contexto geral da epistemologia da prática, perspectiva de formação proposta inicialmente por Schön (2000) para quem a prática profissional deve ser o ponto de partida para a produção teórica.
\end{abstract}

Palavras-chave: Oralidade. Formação de professores. Epistemologia da prática.

Abstract: This text presents reflections on a pedagogical experience of seminar genre production, aiming to analyze the role of orality in multiple dimensions of teaching activity, among which will be highlighted the reflection on teachers' knowledge and beliefs and the development of communication skills. The adopted methodology fits into the context of discussions about teachers' knowledge and professionalization situated in the general context of the epistemology of practice, a education perspective initially proposed by Schön (2000) for whom professional practice should be the starting point for theoretical production.

Keywords: Orality. Teacher education. Epistemology of practice. 
Marcos Bispo dos Santos

\section{Introdução}

A formação de professores é, sob qualquer prisma, um processo multidimensional. As funções sociais da escola e os objetivos educacionais demandam dos professores um conjunto de competências, habilidades, conhecimentos, atitudes e valores como condição necessária para uma prática profissional efetivamente comprometida com a socialização das novas gerações. Dentre os saberes docentes, a oralidade ocupa posição central nos processos interacionais inerentes às atividades direta ou indiretamente ligadas ao ensino, seja em discussões com os colegas e alunos sobre o planejamento das ações pedagógicas, na comunicação com os alunos em sala de aula ou com os pais/responsáveis sobre o comportamento ou desempenho escolar dos estudantes.

Em sociedades letradas, a oralidade que se verifica nas práticas escolares e sociais em geral se classifica, conforme diz Levy (2004) como uma oralidade secundária, isto é, uma oralidade fortemente afetada pela escrita. Desse modo, a oralidade pedagógica compõe-se de uma dimensão centrípeta, que atrai discursos de práticas letradas oriundos das ciências da educação, das ciências ligadas as disciplinas escolares, das políticas educacionais, das normas escolares etc.: de uma dimensão centrífuga, que busca direcionar o discurso letrado para contextos específicos da atuação profissional; e como a oralidade docente não se resume à relação com a escrita, apresenta também a dimensão catalisadora agregar práticas orais e de outras semioses (incluindo aquelas próprias da linguagem digital) nos processos interacionais.

Este texto apresenta reflexões sobre uma experiência pedagógica de produção do gênero seminário, com o objetivo de analisar o papel da oralidade em múltiplas dimensões da atividade docente, entre as quais serão destacadas a reflexão sobre os saberes e crenças dos professores e o desenvolvimento de habilidades de comunicação. A metodologia adotada se insere no contexto das discussões sobre saberes e profissionalização docentes situadas no contexto geral da epistemologia da prática, perspectiva de formação proposta inicialmente por Schön (2000) para quem a prática profissional deve ser o ponto de partida para a produção teórica. Em consequência disso, o estudo da prática pressupõe uma valorização dos saberes profissionais, rompendo, ao mesmo tempo, com a cisão positivista entre ciência e senso comum e com o modelo aplicacionista de formação profissional de professores, caracterizado pela centralidade do conhecimento científico como fonte privilegiada de explicação e fundamentação da prática profissional. 
A experiência relatada neste texto pretende ser uma contribuição no sentido de apontar possibilidades de modelos alternativos de formação inicial de professores de língua portuguesa que permitam a

O seminário

como criação de condições de aprendizagem nas quais as formas de relação com o saber valorizem a implementação de práticas reflexivas sobre saberes experienciais, acadêmicos, profissionais e suas inter-relações. Assim, o seminário constitui uma estratégia de ensino-aprendizagem da prática reflexiva por ser um gênero textual complexo que favorece, no decorrer de suas várias etapas de preparação, o desenvolvimento de habilidades orais e, ao mesmo tempo, a avaliação processual da formação dos futuros professores como atores que submetem suas crenças, valores e saberes próprios ou alheios a exigências de racionalidade.

A prática reflexiva nos moldes aqui propostos exige uma problematização da forma como, em linhas gerais, se dá a relação com o saber na formação inicial do professor de português, nos cursos de licenciatura em Letras. Essa tarefa será realizada na seção "Relação com o saber na formação inicial de professores de português", em que, além da crítica à perspectiva técnica de formação docente, mostrou-se necessária uma crítica da noção de saberes docentes, tal qual formulada por pesquisadores da epistemologia da prática, uma vez que ela tem sido usada, geralmente, em referência aos saberes dos profissionais que já exercem o ofício e não a futuros professores em formação inicial. Na seção "O seminário como estratégia de prática reflexiva e avaliação processual da relação com o saber", os futuros professores desenvolvem atividades de reflexão inicialmente acerca de suas próprias crenças a respeito de determinadas ideias que envolvem a prática da educativa para, em seguida, expor oralmente suas reflexões sobre os saberes acadêmicos acerca dessas crenças. As atividades desenvolvidas nesta seção acionam as três dimensões da oralidade (centrípeta, centrífuga e catalisadora).

\section{Relação com o saber na formação inicial de professores de português}

A escolha da expressão "relação com o saber", que compõe o título desta seção, em lugar da expressão "saberes docentes", mais comum entre os pesquisadores filiados ao paradigma da epistemologia da prática, se deve ao fato de esta ser utilizada para se referir aos profissionais. Da forma como entendo, a expressão escolhida, inspirada na teoria de Charlot (2007), apesar de recobrir também os diversos saberes instrumento de avaliação processual e prática reflexiva na formação inicial de professores 
Marcos Bispo dos Santos

do profissional, se aplica melhor à situação dos futuros professores, a respeito dos quais não se pode ainda falar em saberes docentes como algo consolidado.

Entre os adeptos da epistemologia da prática e da formação do professor reflexivo, é consenso que os saberes docentes necessários ao exercício profissional são mais complexos que os conhecimentos científicos disciplinares tomados de maneira isolada, em razão das contingências da prática e de esta ser atravessada por fatores políticos, socioantropológicos, institucionais, curriculares e aqueles ligados à gestão escolar. $\mathrm{Na}$ formação inicial, o futuro profissional não tem acesso a todos esses fatores, de modo que não é possível fazer referência a seus saberes em relação à prática, mas unicamente em relação aos conhecimentos das disciplinas científicas e/ou acadêmicas que tratam do ensino. Mais tarde, tais saberes vão integrar o conjunto heteróclito dos saberes docentes na forma de saberes disciplinares ou curriculares, conforme a classificação de Tardif (2011).

Diante disso, a análise da relação com o saber do profissional e do estudante precisa ser considerada de modos diferentes. Não é possível generalizar as concepções e práticas de investigação ligadas aos saberes docentes, seja na acepção subjetivista ou psicologizante de várias abordagens etnográficas (TARDIF; GAUTHIER, 2001), do caráter social do saber docente (TARDIF, 2011), do acessibilismo epistemológico, ou seja, da crença de que o sujeito sempre pode acessar seu próprio conhecimento (SCHÖN, 2000), do habitus ou inconsciente prático (PERRENOUD, 2002), e transferi-las para o estudo da relação com o saber dos professores em formação inicial, visto que todas essas perspectivas têm como ponto de partida o conhecimento da prática ou saberes experienciais (TARDIF, 2011), ainda ausentes nos estudantes ou conhecidos de maneira parcial e intuitiva.

Na avaliação de Tardif (2011), no modelo da racionalidade técnica, a formação universitária do professor aborda a pesquisa e as práticas de ensino de um ponto de vista normativo. Ou seja, os professores e pesquisadores se interessam mais pelo que os estudantes e professores da educação básica deveriam ser, fazer e saber do que pelo que são, fazem e sabem efetivamente. Em consequência disso, homogeneízam os sujeitos, os saberes e as práticas formativas, de maneira que não há espaço para a individualização dos percursos; não interessa a história de vida dos futuros professores, seus projetos de vida, 
suas crenças acerca do papel social do professor e seus valores; suas condições em relação a saberes básicos que deveriam ter construídos ao longo da educação básica.

A concepção do professor como um técnico que aplica conhecimentos científicos em seu ofício torna irrelevante o conhecimento da vida dos estudantes e, por conseguinte, não há espaço para a identificação de suas necessidades particulares de aprendizagem, o que demandaria a proposição de percursos formativos individualizados. Trata-se, portanto, de um modelo em que predomina a pressuposição ou presunção de verdade e autossuficiência do conhecimento científico, em torno do qual se confirma o caráter normativo da formação, em detrimento de um modelo que valorize a compreensão da educação como um fenômeno intrinsecamente complexo e a construção de competências e ha-

O seminário como instrumento de avaliação processual e prática reflexiva na formação inicial de professores

bilidades para ensinar, que podem ser mais produtivamente abordados por um viés reflexivo que normativo.

Todos esses problemas são mais facilmente identificáveis pelos futuros profissionais nos períodos dos estágios obrigatórios, ou seja, nos momentos de contato efetivo com o contexto da prática. Diante das questões relativas aos saberes docentes suscitadas pela epistemologia da prática, não é exagero afirmar que o estágio obrigatório, no modelo aplicacionista, pode ser mais acertadamente caracterizado como um componente meramente formal da estrutura curricular. Isso se deve, em primeiro lugar, ao fato de que a complexidade da prática, no contexto escolar, contrasta com a fragmentação própria da lógica disciplinar a que os estudantes são submetidos. As disciplinas funcionam durante o curso de maneira autônoma, sem relação entre si, e são regidas por questões de conhecimento e não por questões de ação. Ou seja, "numa disciplina, aprender é conhecer. Mas, numa prática, aprender é fazer e conhecer fazendo" (TARDIF, 2011, p. 271).

Nessa perspectiva, a capacidade de refletir sobre os saberes acadêmicos em sua correlação com os saberes da prática educativa deve-se tornar um dos objetivos centrais da formação inicial dos professores, tendo em vista o propósito de garantir o desenvolvimento de competências básicas necessárias ao exercício da profissão. Esse processo deve considerar como ponto de partida as crenças dos estudantes sobre os vários aspectos que envolvem a educação, transformando-as em objetos de reflexão segundo regras de racionalidade que levam em conta fatores epistemológicos, axiológicos e praxiológicos. 
Marcos Bispo dos Santos
Na próxima seção, apresento o relato de uma atividade pedagógica de produção do gênero seminário, contemplando etapas de delimitação temática, problematização, preparação e apresentação. Para que o seminário funcionasse como uma estratégia de prática reflexiva e avaliação processual foi necessário reconfigurá-lo teoricamente, de modo a garantir que, em cada uma de suas fases, fosse possível colocar os estudantes em situações que lhes provocassem a refletir e, ao mesmo tempo, permitissem a avaliação do processo, atividade necessária para (re) orientar as ações pedagógicas em função dos objetivos estabelecidos. 0 trabalho se desenvolveu ao longo de um semestre letivo, na disciplina Prática Pedagógica III, cuja ementa prevê uma abordagem didática, geral e específica do português, sobre temas como teorias do currículo, planejamento pedagógico, pedagogia de projetos e suas relações com o ensino de Língua Portuguesa.

A condução pedagógica da disciplina em estrita observância aos conteúdos estabelecidos na ementa representaria o alinhamento ao modelo de ensino normativo, que busca definir o que os estudantes devem ser, saber e fazer, sem qualquer preocupação com quem eles são e o que sabem, conforme a avaliação de Tardif (2011). Observar esses aspectos é fundamental numa proposta de formação reflexiva. Como eu já acompanhava a turma pelo terceiro semestre consecutivo, pude observar algumas de suas crenças acerca de temas ligados aos conteúdos programáticos da disciplina que, se não fossem adequadamente tratados num viés reflexivo, poderiam comprometer a compreensão da natureza do planejamento pedagógico e suas finalidades no processo educacional. Por essa razão, foram selecionados para o seminário temas ligados à sociologia, da filosofia e da psicologia da educação como: identidade docente, influência das condições socioeconômicas no processo de ensino-aprendizagem, funções da escola como instância de educação formal, relação entre família e escola, metodologias de ensino e funções da avaliação.

Para que um professor tome como seu um projeto educacional, como postulam Gimeno Sacristán e Pérez Gómez (1998), é necessário que ele, de fato, acredite nesse projeto. Contudo, se suas crenças forem conflitantes quanto aos objetivos e viabilidade desse projeto, ele se torna impraticável. Nesse sentido, o trabalho pedagógico sobre as crenças dos futuros professores constitui etapa fundamental da formação reflexiva. Aqui é importante ressaltar que a crítica ao 
normativismo da perspectiva técnica de formação docente não se confunde com a negação de qualquer norma no processo educacional. A avaliação, como dispositivo de acompanhamento, diagnóstico

O seminário

como

e orientador de ajustes das ações educativas em função dos objetivos estabelecidos, é a prova cabal de que qualquer projeto de formação é normativo em maior ou menor grau. A diferença está na finalidade última de cada modelo. Enquanto na perspectiva técnica a teoria apriorística se apresenta como definidora da prática, na perspectiva reflexiva, o saber se atualiza e se (re)constrói constantemente em face das contingências da prática.

\section{0 seminário como estratégia de prática reflexiva e avaliação processual da relação com o saber}

Como prática discursiva nos meios acadêmicos, o seminário se caracteriza como um evento ou espaço destinado à apresentação de resultados de projetos de pesquisa ou à divulgação de estudos entre os pares. Em cursos de graduação ou pós-graduação, o seminário costuma ser utilizado como estratégia pedagógica que favorece o compartilhamento, entre professores e alunos, das discussões de textos que constituem as referências teóricas de determinada disciplina. Em geral, a metodologia consiste na exposição das ideias do texto, de maneira individual ou em grupos, e a avaliação tem como foco o produto (a qualidade da apresentação) e não o processo que se desenvolve até lá. Os critérios de avaliação geralmente não são muito claros, ficando muitos aspectos subordinados ao arbítrio do avaliador, ou seja, do professor e, no caso das apresentações em grupo, a avaliação dificilmente contempla aspectos relativos à participação ou ao envolvimento de cada membro na execução das tarefas. Visto dessa forma, o seminário como estratégia pedagógica constitui uma variação da metodologia transmissiva, exercida de maneira compartilhada, mas igualmente voltado para a apropriação dos saberes acadêmicos.

De acordo com Severino (2002), o seminário, como um método de ensino e atividade didática em cursos universitários, tem como objetivo levar todos os participantes a uma reflexão aprofundada de determinado problema, a partir de textos e em equipe. Nessa perspectiva, o seminário é entendido como uma atividade de formação do leitor, que deve ser conduzida pelo professor responsável. A proposta do autor ressalta a importância de uma fase preliminar de leitura e análise textual dos instrumento de avaliação processual e prática reflexiva na formação inicial de professores 
Marcos Bispo dos Santos

textos selecionados para o tratamento de determinado tema ou problemática. Sua metodologia prevê três possibilidades de estratégias de preparação e realização do seminário para a apresentação dos grupos:

I) O texto-roteiro didático: composto de três unidades - apresentação da temática do seminário, breve visão de conjunto da unidade e esquema geral do texto -, trata-se de um material elaborado pelo professor a partir do texto que constituirá a referência básica para o seminário. 0 texto-roteiro apresenta o tema do texto básico, que será também o tema do seminário, suas unidades estruturais, seus principais conceitos, ideias e fundamentos teórico-metodológicos, problematiza e levanta questões importantes para serem discutidas no seminário e finaliza com indicações de leitura que permitam aprofundar as discussões sobre o tema. Os expositores devem apresentar uma síntese do raciocínio do autor, de acordo com a análise temática do texto base, e apresentar possibilidades de respostas para os problemas e questões apresentadas no texto-roteiro didático. Para isso, a leitura das referências complementares é fundamental.

II) O texto-roteiro interpretativo: representa uma alternativa ao texto-roteiro para ser utilizado em turmas mais avançadas ou amadurecidas academicamente. Nele, o autor, o estudante que apresentará o seminário, contempla todos os pontos mencionados, mas abandona o estilo expositivo em favor de um discurso personalizado. Nas palavras de Severino (2002, p. 67): “o responsável pelo seminário dedica-se à elaboração de um texto-roteiro no qual desenvolveu intencionalmente uma reflexão que, quanto mais pessoal for, maior contribuição dará ao grupo". Nesse modelo, os demais participantes devem ter compreendido o texto básico para debater com o responsável no dia da apresentação.

III) O texto-roteiro de questões: trata-se de um desdobramento do roteiro-didático. Neste caso, o responsável pelo seminário entrega aos demais, com antecedência, um conjunto de questões ou problemas devidamente formulados a partir do texto básico. Esse modelo exige atenção quanto à necessidade de realização de pesquisa e reflexão para evitar perguntas superficiais e garantir a profundidade das discussões. 
As estratégias propostas por Severino apresentam alternativas às práticas espontaneístas de realização do seminário ao integrar objetivos didáticos a atividades sistemáticas de leitura, reflexão, proble-

O seminário como instrumento de avaliação processual e prática reflexiva na formação inicial de professores Tais resultados, positivos ou negativos, costumam ser simplesmente registrados no histórico dos alunos. Dessa forma, o termo avaliação seria, a rigor, inadequado, uma vez que o que efetivamente se faz é um exame dos erros e acertos, tendo em vista o atendimento a uma burocracia escolar voltada para fins de certificação.

Conforme define Luckesi (2011, p. 265), “a avaliação da aprendizagem na escola configura-se como um ato de investigar a qualidade do desempenho dos educandos, tendo por base dados relevantes, decorrentes de sua aprendizagem e, se necessário, numa intervenção, a fim de corrigir os rumos da ação". A separação entre metodologia de ensino e avaliação da aprendizagem negligencia duas condições prévias que o autor entende como necessárias a todo ato de avaliar: a disposição psicológica de acolher a realidade como ela é e a escolha da teoria com a qual fará sua aventura de investigar. A avaliação deve ser entendida como um processo complexo, contínuo, que está presente nos atos educativos desde sua concepção até a análise dos resultados finais. Dada sua importância na investigação sobre o trabalho pedagógico e na identificação das necessidades de intervenção, a avaliação apresenta um caráter intrinsecamente cíclico, ininterrupto: o final de uma fase sempre pode representar o início de outra, com o objetivo de corrigir possíveis problemas. Vista dessa forma, a avaliação é, por natureza, processual e formativa.

Nesta seção, apresento o relato de uma experiência em que o seminário foi utilizado como estratégia pedagógica de formação reflexiva do professor de língua portuguesa e de avaliação processual da aprendizagem no âmbito da epistemologia da prática. Nessa perspec- 
Marcos Bispo dos Santos

tiva, foi necessária uma dupla ruptura didático-pedagógica: a substituição da metodologia transmissiva por uma abordagem problematizadora dos saberes acadêmicos e a mudança de foco, no processo avaliativo, do produto para o processo. A metodologia foi inspirada nas estratégias de Severino por entender que, apesar de sua exposição revelar compromisso precípuo com os saberes acadêmicos, elas podem ser adaptadas a uma formação reflexiva. Dada sua limitação quanto a uma teoria da avaliação, complementei a proposta com pressupostos da avaliação processual postulados por Perrenoud (1999), Hadji (2001), Luckesi (2011) e Gil (2011), e a dividi em quatro etapas delimitação temática, problematização, preparação e apresentação -, que serão delineadas e discutidas a seguir.

\subsection{A delimitação temática}

A proposta pedagógica desenvolvida integrou o conjunto de atividades do componente curricular Prática Pedagógica III, do curso de Letras Língua Portuguesa e Literaturas, de uma universidade pública do estado da Bahia, no primeiro semestre do ano de 2016. A ementa da disciplina estabelece os aspectos que devem ser observados no curso: Estudo das diferentes formas de planejamento educacional, pedagogia de projetos, projetos pedagógicos. Discussão das diferentes teorias de currículo numa perspectiva histórica e suas interferências no ensino de língua portuguesa e literaturas de língua portuguesa.

Pela ementa, vê-se que o currículo de curso, como documento de natureza normativa, projeta o componente curricular referido como espaço para a construção de saberes docentes teóricos necessários à construção dos saberes práticos. Altet (2001) propõe uma tipologia que permite compreender a natureza desses saberes no processo formativo e na atuação profissional do professor. Os saberes teóricos são da ordem dos declarativos ou conceituais e se dividem em: i) saberes a serem ensinados, que compreendem os disciplinares, os constituídos pelas ciências e os tornados didáticos, com o propósito de permitir aos alunos a aquisição de sabres; ii) saberes para ensinar, abrangendo os conhecimentos pedagógicos sobre a gestão interativa da sala de aula, as didáticas das diferentes disciplinas e os saberes da cultura que os está transmitindo. Os saberes práticos são aqueles decorrentes das experiências cotidianas da profissão, contextualizados e adquiridos em situações de trabalho. Tais saberes se dividem em: i) saberes sobre a prática, isto é, saberes 
procedimentais acerca do "como fazer"; ii) saberes da prática, oriundos da experiência, produto da ação que, na avaliação do profissional, teve êxito, da práxis e ainda os saberes condicionais (saber quando e onde utilizar determinados saberes).

Dada a abrangência de saberes contidos na ementa e a extensão de sua carga horária (105 horas-aula), apresentei aos alunos a sugestão de dividir a disciplina em quatro módulos que abrangessem aspectos da didática geral e específica da língua portuguesa: i) teoria didática geral, abrangendo os temas relacionados às teorias do currículo, planejamento e pedagogia de projetos; ii) didática da leitura e produção textual; iii) didática da gramática; iv) didática da literatura. Expliquei que o primeiro módulo nos permitiria construir saberes básicos que seriam fundamentais para orientar a seleção e a organização dos conteúdos, bem como a escolha das estratégias de ensino e de avaliação que seriam objetos de estudo nos demais módulos. Todos concordaram com a proposta.

Em seguida, iniciei a exposição da metodologia que pretendia utilizar, o seminário, para alcançarmos o objetivo do primeiro módulo, a saber, refletir sobre as contribuições e limites das teorias didático-pedagógicas no currículo e na atuação dos professores de língua portuguesa. Por se tratar de uma turma que estava comigo pelo terceiro semestre consecutivo, fiz uma breve avaliação do estado de cada um, com base no desempenho demonstrado nos seminários já realizados, apontando avanços e necessidades de aprendizagem que ainda persistiam. Num curso de formação de professores, o seminário, além de uma metodologia de estudos, deve ser também um recurso para o desenvolvimento de competências discursivas ligadas à oralidade, extremamente necessárias ao exercício da profissão, tais como posicionamento e movimentação corporal, dicção, organização do discurso, articulação entre discurso e recursos de exposição (quadro, projetor, TV etc.), leitura de comportamento do público para medir a qualidade da recepção.

Diante disso, argumentei que o formato de seminário que iria propor permitiria o enfrentamento de alguns problemas que ainda persistiam no campo da expressão oral e quanto ao desenvolvimento de uma postura mais reflexiva e racional diante das teorias acadêmicas e de crenças sobre o ensino. 0 sucesso de tal metodologia estava condicionado, no entanto, à adoção de uma concepção da avaliação como um processo formativo: 
Marcos Bispo

dos Santos
A ideia de avaliação formativa sistematiza esse funcionamento, levando o professor a observar mais metodicamente os alunos, a compreender melhor seus funcionamentos, de modo a ajustar de maneira mais sistemática e individualizada suas intervenções pedagógicas e as situações didáticas que propõe, tudo isso na expectativa de otimizar as aprendizagens [...]. Essa concepção se situa abertamente na perspectiva de uma regulação intencional, cuja intenção seria determinar ao mesmo tempo o caminho já percorrido por cada um e aquele que resta a percorrer com vistas a intervir para otimizar os processos de aprendizagem em curso. (PERRENOUD, 1999, p.89)

Nessa perspectiva, busquei, ao longo do processo, observar cada estudante individualmente para ajustar as intervenções de maneira que pudesse abordar satisfatoriamente suas necessidades formativas. Isso se deu desde a definição dos temas para o seminário, passando pelas fases de problematização e preparação, até as discussões ocorridas nos momentos de apresentação.

\subsection{A problematização}

Um dos problemas da perspectiva técnica de formação docente, de acordo com a avaliação de Tardif (2011), é que nele os alunos são tratados como espíritos virgens e suas crenças ou representações anteriores a respeito do ensino não são levadas em conta. Por essa razão, o processo formativo se limita a transmitir informações, sem a devida atenção aos filtros cognitivos, sociais e afetivos que orientam o processamento de informações pelos futuros profissionais. Diante disso, o autor ressalta que

[...] esses filtros permanecem fortes e estáveis através do tempo, pois provém da história de vida dos indivíduos e de sua história escolar. Consequentemente, a formação para o magistério tem um impacto pequeno sobre o que pensam, creem e sentem os alunos antes de começar. Na verdade, eles terminam sua formação sem terem sido abalados em suas crenças, e são essas crenças que vão reatualizar no momento de aprenderem a profissão na prática e serão habitualmente reforçadas pela socialização na função de professor e pelo grupo de trabalho nas escolas, a começar pelos pares, os professores experientes. (TARDIF, 2011, p. 273) 
$\mathrm{Na}$ epistemologia da prática, os saberes prévios constituem ponto de partida para a compreensão das atitudes dos futuros profissionais. Essa perspectiva se alinha à concepção de avaliação como prática co-

O seminário como instrumento de avaliação processual e prática reflexiva na formação inicial de professores

A etapa de problematização teve como objetivo levantar os conhecimentos prévios dos futuros professores acerca de alguns temas bastante controversos no meio escolar e que afetam profundamente o desempenho dos profissionais que atuam guiados pelo habitus ou inconsciente prático: funções sociais da escola, a escola frente às desigualdades sociais, avaliação e reprovação, sucesso e fracasso escolar, identidade docente, metodologias de ensino, qualidade da escola pública versus escola particular. Os alunos foram instados a se manifestar diante das seguintes questões:

1) As condições socioeconômicas dos estudantes prejudicam os processos de ensino-aprendizagem?

2) A função mais importante da escola é formar cidadãos críticos?

3) Educação se aprende em casa e cabe à escola apenas ensinar conteúdos?

4) Para ser um bom professor, dom e vocação são suficientes?

5) Conteúdo dado é conteúdo aprendido?

6) Os alunos aprendem mais com atividades lúdicas?

7) A repetência melhora o desempenho dos estudantes?

Os problemas foram extraídos ou adaptados da matéria 15 mitos da educação (FERNANDES, 2017), publicada pela revista Nova Escola, que apresenta 15 ideias falsas que circulam no cotidiano escolar como verdades. No texto, cada mito é descrito e refutado de maneira bem sintetizada e sua exposição é finalizada com a utilização de um argumento de 
autoridade. A seleção de problemas ou mitos não se deu de forma aleatória. Levou em conta as observações sobre a forma como os alunos se posicionavam a respeito dos temas escolhidos em semestres anteriores do curso. Durante as discussões destinadas à problematização, todos os sete alunos da turma demostraram adesão a um ou mais mitos, de maneira total ou parcial, e esses dados foram importantes para as tomadas de decisão acerca do que seria feito nas próximas etapas.

Marcos Bispo dos Santos

\subsection{A preparação}

A fase de preparação para as apresentações do seminário foi dividida em três etapas. Na primeira, distribuímos os temas. Cada aluno ficou responsável por uma das questões da problematização. Essa distribuição não se deu de forma aleatória, através de sorteio ou de acordo com a afinidade subjetiva dos estudantes com algum dos problemas, mas considerou a forma como cada um se posicionava em relação a eles. Assim, foi designado para cada aluno o problema ou mito relativo à educação que contava com sua adesão. Levando em conta as crenças dos futuros professores, o seminário tinha como objetivo promover uma prática reflexiva que contemplasse a submissão das próprias representações a exigências de racionalidade.

Embora a reformulação das próprias crenças fosse um objetivo do processo e ao mesmo tempo um critério de avaliação, os alunos não foram informados disso. Com isso, pretendia evitar que assumissem posturas ou discursos que julgassem ser aqueles esperados pelo professor, com o objetivo de serem bem avaliados. Gil (2011) adverte que a avaliação costuma ser utilizada de maneira subjetiva e arbitrária por muitos professores universitários, contrariando os pressupostos da avaliação formativa. Sabendo disso, é comum que os alunos se adaptem às "regras do jogo", fazendo simplesmente o que deles se espera para ampliar as chances de obter resultados satisfatórios na avaliação somativa.

Esse quadro torna complexa a atividade de avaliar quando o objetivo do processo formativo se refere a competências e habilidades ligadas à prática reflexiva por não se tratarem de objetos que podem ser delimitados em unidades letivas objetivamente definidas. Consequentemente, essa mudança de paradigma da avaliação rompe com determinadas crenças dos estudantes sobre como devem avaliar seu desempenho ou sobre como deverá ser sua preparação para realizar as atividades avaliativas. 
A avaliação formativa deve considerar a relevância dos aspectos subjetivos nas ações dos estudantes, em todas as fases do processo educativo, de maneira que as intervenções docentes sejam efetivas para a O seminário como consecução dos objetivos. Numa perspectiva de formação que se propõe a trabalhar com a reflexão sobre as próprias crenças e consequente revisão daquelas que se mostram incompatíveis com as funções sociais da educação e com o perfil ético-político dos professores, é preciso levar em conta que, em geral, temos a tendência de defender nossas convicções, mesmo que não sejamos capazes de justificá-las. E isso não é diferente com os futuros professores. Diante disso, entendo que o processo de revisão das próprias crenças deve-se dar num conjunto de situações didáticas que contemplem estratégias que favoreçam a autorregulação das aprendizagens por parte dos estudantes. Por conta disso, a decisão instrumento de avaliação processual e prática reflexiva na formação inicial de professores de não explicitar antecipadamente que a revisão das próprias crenças, durante e após as práticas reflexivas, era um critério de avaliação foi uma medida que visava evitar um processo formativo estritamente condutista, incompatível com a perspectiva de formação do professor reflexivo.

A segunda etapa da fase de preparação consistiu em atividades de leitura coletiva e discussão de textos que permitissem ampliar a compreensão dos problemas do seminário. Diferentemente do que propõe Severino (2002), não partimos de um único texto básico. Embora a matéria da revista Nova Escola tenha sido o ponto de partida para a definição dos temas de cada apresentação, não poderíamos considerá-la como um texto básico devido à superficialidade com que tratava tanto a caracterização quanto a refutação de cada mito. Assim, selecionei textos de dois autores que abordam, de maneira direta ou indireta, todos os mitos tratados na matéria da revista numa perspectiva crítica e problematizadora. Diante disso, nesta etapa, realizamos não apenas atividades de formação do leitor, mas também de pesquisa.

O primeiro texto - As funções da escola: da reprodução à reconstrução crítica do conhecimento e da experiência (PÉREZ GÓMEZ, 1998) - apresenta uma discussão sobre o papel da escola no processo de socialização, iniciando por uma análise crítica da teoria da reprodução (BOURDIEU; PASSERON, 2010), que concebe a escola como uma instância destinada a reproduzir a desigualdade social, e chegando à compreensão da função educativa como um processo de humanização baseado em dois pressupostos: o desenvolvimento da função compensatória, por meio do qual 
Marcos Bispo dos Santos

a escola deveria buscar o equilíbrio entre o currículo comum e a estratégia didática da diferenciação dos percursos em face da heterogeneidade dos sujeitos dentro de uma escola compreensiva; e a reconstrução crítica do conhecimento e da experiência, por meio da qual a escola deve provocar e facilitar a reconstrução dos conhecimentos, atitudes e formas de conduta que os alunos assimilam direta e acriticamente nas práticas sociais de sua vida anterior e paralela à escola. 0 autor fundamenta suas críticas à teoria da reprodução em teses do individualismo metodológico e do relacionalismo (BOUDON, 2016; LAHIRE, 2008; VAN HAECHT, 2008), que questionam o determinismo socioeconômico nas ações dos sujeitos individuais.

Os demais textos das referências obrigatórias foram dois capítulos do livro "Desenvolver competências ou ensinar saberes? A escola que prepara para a vida" (PERRENOUD, 2013). o capítulo 3 - Competências e situações - discute a noção de competência e seu potencial como conceito nuclear na definição dos objetivos da educação. Ao definir a competência como a capacidade de mobilizar recursos (saberes declarativos, processuais e condicionais) para resolver situações problemáticas, o autor propõe uma nova forma de conceber o currículo diante do objetivo da escola de preparar o estudante para vida. No capítulo 4 - Confusões conceituais -, o autor se propõe a dirimir equívocos muito comuns nos meios acadêmico e escolar diante do tema da educação voltada para o desenvolvimento de competências: a confusão entre situações de formação e situações de referência, uma suposta oposição entre conhecimentos e competências, as relações entre disciplinas e competências, a diferença entre competências e habilidades, a sedução das competências transversais, a relação entre competências e objetivos, a relação entre competências e construtivismo.

A metodologia utilizada em sala para a leitura dos textos buscou evitar que o professor fosse visto como o detentor do conhecimento ou como o único responsável pelo acontecimento da aula, ou seja, o propósito era desconstruir a interpretação do processo de ensino-aprendizagem como transmissão e memorização. A ideia era que os alunos se sentissem corresponsáveis pela gestão das discussões em sala. Para cada texto, fizemos uma distribuição das seções que o compunha entre o professor e os alunos, de modo que cada aluno fizesse a exposição de, no mínimo, duas unidades textuais. É importante ressaltar que foi necessário atribuir uma pontuação a essas atividades como parte da ava- 
liação somativa, devido a solicitações dos estudantes. Sobre o problema da relação entre avaliação formativa e somativa no ato educativo, Hadji (2001, p. 68) pondera que:

O seminário

como

instrumento

Ainda que avaliar não seja medir, e que não haja, em última hipótese, avaliação senão qualitativa, é possível, com a condição de não cometer o erro que consiste em acreditar que basta observar o real para avaliar, buscar uma maior objetividade, no que tange ao referido, na consideração de dados quantificáveis.

Do ponto de vista da tradição escolar, a atribuição de pontos ou notas se fixou ao mesmo tempo como um mecanismo de avaliação classificatória/certificatória (aquela que pressupõe o aproveitamento quande avaliação processual e prática reflexiva na formação inicial de professores titativo como condição para a progressão à série/ano seguinte ou para a conclusão do curso) e de distribuição de recompensas, com impactos sobre a motivação e a imagem que o estudante constrói de si mesmo e passa aos outros sobre sua condição intelectual. Situações como essas demonstram que o futuro profissional ainda vive um dualismo identitário, oscilando entre ser aluno e ser professor, sendo natural que penda para um lado ou outro, de acordo com o que lhe parecer conveniente em cada situação. Desse modo, atentando para as observações de Hadji, não encarei como algo problemático a atribuição de pontos à exposição de cada aluno e estabeleci os critérios que serviriam de parâmetros tanto para a minha (auto)avaliação quanto para a (auto)avaliação deles sobre o processo. Para cada seção ou unidade textual, os alunos deveriam: i) situar a unidade no contexto geral do texto ou capítulo; ii) apresentar o problema, os objetivos e a justificativa da seção; iii) identificar a tese, argumentos e contra-argumentos utilizados pelo autor; iv) identificar a conclusão da unidade; v) relacionar as ideias da seção ao problema ou mito que será objeto de sua apresentação no seminário. Durante a discussão, os demais alunos deveriam, além de participar das discussões (todos deveriam ler todos os textos selecionados), tentar estabelecer relações entre o conteúdo da apresentação e problemas ou mitos sob sua responsabilidade para o seminário.

Antes da exposição dos alunos, fiz a exposição e discussão de uma seção do primeiro texto, que seria uma espécie de modelo de como eles deveriam se apresentar, em que destaquei os pontos que eles deveriam observar e os procedimentos orais a serem utilizados, tais como iden- 
Marcos Bispo dos Santos

tificação do tema da seção, relação desse tema com o objetivo geral do texto, identificação das ideias principais e argumentos utilizados para sustentá-las, conclusões, autor e relações com o contexto escolar e consequências para a formação de professores. Essa atividade se aproximou bastante daquilo que Severino (2002) definiu como texto-roteiro didático. Apesar disso, foram frequentes os casos em que precisei intervir durante as apresentações para garantir a observância de todos os critérios de avaliação. Tais intervenções consistiram em perguntas que provocavam os estudantes a identificar lacunas em suas exposições ou a refletir sobre a relação do texto com os temas do seminário.

A última etapa da fase de preparação foi a elaboração da apresentação oral. o desafio era conseguir manter o acompanhamento individualizado das aulas nas atividades extraclasse, reforçando a concepção de aprendizagem como um processo de autorregulação por meio de estratégias pedagógicas adequadas, conforme destaca Perrenoud (1999, p. 96),

Para aprender, o indivíduo não deixa de operar regulações intelectuais. Na mente humana, toda regulação, em última instância, só pode ser uma autorregulação. Pelo menos se aderirmos às teses básicas do construtivismo: nenhuma intervenção externa age se não for percebida, interpretada, assimilada por um sujeito. Nessa perspectiva, toda ação educativa só pode estimular o autodesenvolvimento, a autoaprendizagem, a autorregulação de um sujeito, modificando seu meio, entrando em interação com ele.

Nesse sentido, propus duas estratégias que permitiriam aos estudantes a compreensão da aprendizagem como um processo de autorregulação e o desenvolvimento da postura reflexiva. Antes disso, porém, foi necessário apresentar a eles a estrutura da apresentação. As apresentações deveriam partir da caracterização do problema ou mito, conforme descrito na matéria da revista Nova Escola, e da refutação apresentada. Em seguida, deveriam discutir as consequências educacionais decorrentes da atribuição de valor de verdade ao mito pelos professores. Após isso, problematizariam as ideias contidas na matéria da Revista e as próprias crenças acerca delas, a partir dos textos trabalhados na etapa de leitura. 
No tocante às estratégias pedagógicas empregadas nessa etapa, a primeira foi a discussão de três textos complementares compartilhados no grupo da turma criado na rede social Facebook. O primeiro, O objetivo O seminário como da educação por competência é o pleno desenvolvimento da pessoa (ZABALA; ARNAU, 2016), apresenta uma síntese das discussões dos textos utilizados na etapa de leitura, contemplando também os problemas apontados nos mitos da matéria da revista Nova Escola. O segundo foi uma entrevista do idealizador da Escola da Ponte de Portugal, José Pacheco (2017), publicada na versão digital do jornal Folha de São Paulo, que apresenta os métodos globalizados como uma alternativa educacional à pedagogia tradicional. O terceiro, Progressão continuada não é aprovação automática (ALMEIDA, 2017), como indica o título, propõe-se a desfazer equívocos decorrentes da identificação entre progressão continuada e aprovação instrumento de avaliação processual e prática reflexiva na formação inicial de professores automática. Solicitei aos alunos que lessem os textos e que utilizassem o grupo criado no Facebook para apresentar possíveis dúvidas ou questões sobre seu conteúdo. Nenhum deles utilizou o recurso digital como espaço de discussões. Optei por não fazer intervenções quanto a isso e observar se, durante as apresentações do seminário, as ideias dos textos complementares seriam utilizadas por eles.

A segunda estratégia pedagógica foi a realização de um fichamento, utilizando a ferramenta de escrita colaborativa Google Docs, disponível gratuitamente na internet. Os alunos foram orientados a retomar a leitura dos textos, obrigatórios e complementares, para selecionar os aspectos relativos a seus respectivos temas, de maneira que pudessem organizar suas reflexões e exposições orais. Adverti-os de que não se tratava de um fichamento integral do texto, mas de um processo de análise textual que deveria resultar na seleção apenas das ideias referentes a seus temas. A escolha da ferramenta digital referida se deu por se tratar de um recurso que permitiu o compartilhamento do texto comigo, para fins de acompanhamento do processo e possíveis intervenções em tempo real, inclusive com a possibilidade de interação via chat, para eventuais orientações individualizadas. A elaboração do fichamento foi outra atividade para a qual os alunos solicitaram a atribuição de nota. Apenas um dos alunos não elaborou o fichamento e, quando questionado a respeito, alegou problemas pessoais. Os demais puderam contar com minhas intervenções que os auxiliaram a estabelecer relações entre os textos fichados e seus temas. 
Marcos Bispo dos Santos

\subsection{As apresentações}

Conforme relatado na fase anterior, a distribuição dos temas entre os alunos levou em conta a adesão que manifestaram aos mitos apresentados na matéria da revista Nova Escola, tendo em vista o objetivo de, no âmbito da prática reflexiva, criar situações que os instassem a submeter suas crenças a exigências de racionalidade. Ressaltei que esse foi um critério de avaliação não declarado no início para evitar que demonstrassem mudanças apenas no discurso, por entenderem que isso seria o bastante para conseguirem boas notas. Deixei em aberto também a falta de discussões sobre a leitura das referências complementares como critério que permite avaliar a autonomia e a autorregulação dos processos de aprendizagem. Tais critérios são muito importantes porque informam sobre como o futuro professor lida com sua responsabilidade epistêmica. Além desses critérios "ocultos", outros foram explicitamente apresentados aos alunos: a observância aos elementos estruturais estabelecidos para a organização das apresentações, dicção, envolvimento do grupo, organização, capacidade de reflexão, disposição corporal e articulação adequada entre oralidade e recursos auxiliares (quadro, projetor etc.). De modo geral, todos demonstraram bom desempenho quanto às habilidades relativas à expressão oral. As observações seguintes se restringirão ao desempenho deles quanto aos critérios voltados para a formação do professor reflexivo. Após cada apresentação, fiz algumas intervenções com perguntas para provocar algumas reflexões ou preencher lacunas da exposição.

A aluna que tratou do primeiro problema ou mito - As condições socioeconômicas dos estudantes prejudicam os processos de ensino-aprendizagem? - apresentou boa compreensão dos textos lidos e importantes reflexões sobre si e sobre a situação escolar. Mesmo sem relacionar o mito de que as condições socioeconômicas dos alunos pobres dificultam sua aprendizagem ao determinismo socioeconômico da teoria da reprodução de Bourdieu e Passeron (2010), a partir das críticas de Pérez Gómez (1998) a essa perspectiva da sociologia da educação, concluiu, contrariando sua antiga crença, que o maior problema está na homogeneização dos processos educativos e na desconsideração da diversidade sociocultural. Ou seja, a escola desconsidera a necessidade de desenvolver práticas pedagógicas diferenciadas com base no diagnóstico das necessidades de aprendizagem dos alunos e atribui ao estudante, à família ou ao sistema toda a responsabilidade pelo fracasso escolar. 
O aluno responsável por apresentar discussões a respeito do segundo problema ou mito - A função mais importante da escola é formar cidadãos críticos? - não participou de maneira adequada das etapas anteriores. Foi bastante ausente das aulas e, no dia da apresentação, apenas reafirmou sua adesão ao mito de que a função principal da escola é formar o cidadão crítico. Trata-se também de um mito com muitas ligações com a teoria da reprodução e com algumas leituras da crítica marxista, segundo a qual a ideologia da classe dominante se impõe às classes dominadas através de instituições como a escola. Nessa perspectiva, o professor que não desenvolvesse práticas de ensino que evidenciassem como tal ideologia mascararia a realidade seria um agente a serviço da reprodução das desigualdades sociais. Após essas considerações, o aluno foi orientado a reorganizar sua apresentação para a semana seguinte, mas ele optou por desistir da disciplina, alegando que, devido a problemas pessoais, não teria condições de realizar a atividade.

$\mathrm{Na}$ exposição do terceiro problema ou mito - Educação se aprende em casa e cabe à escola apenas ensinar conteúdos? -, a aluna responsável demonstrou boa capacidade de reflexão ao afirmar que modificou sua forma de compreender a função social da escola, com base, principalmente, nas discussões de Zabala e Arnau (2016) e Perrenoud (2013). Esses autores defendem a impossibilidade de se separar, de maneira estanque, as responsabilidades da escola e da família no processo educativo voltado para o desenvolvimento de competências, uma vez que elas se referem a fatores pessoais, interpessoais, sociais e profissionais. A noção de transversalidade, estreitamente vinculada à de competência, amplia o escopo de saberes que compõem uma disciplina, determinando uma nova compreensão do que tradicionalmente se entende por conteúdos disciplinares na escola.

O aluno responsável pelo quarto problema ou mito - Para ser bom professor, dom é vocação são suficientes? - não participou adequadamente das etapas anteriores e foi mais um a reafirmar adesão ao mito. Em todos os textos lidos, verificou-se a ênfase na necessidade de qualificação docente para cumprir seu papel no combate às desigualdades sociais. Tardif (2011), por exemplo, ressalta o caráter social dos saberes docentes, o que contrasta com a ideia de que suas competências seriam resultantes da posse de um dom natural. Com base nessas considerações, o aluno foi orientado a reorganizar sua apresentação para a 
Marcos Bispo dos Santos semana seguinte. Como sua segunda exposição contou com o filtro dessas observações, não foi possível avaliar se ele, de fato, modificou suas crenças, ou se estava adotando a posição que dele se esperava.

A aluna responsável por discutir o quinto problema ou mito Conteúdo dado é conteúdo aprendido? - admitiu sua crença na ideia de que, se o professor “dava o conteúdo", fazia o necessário para isentá-lo de qualquer responsabilidade quanto ao fracasso escolar. Esse posicionamento refletia sua adesão à concepção de ensino baseada na transmissão de informações como suficiente para determinar a aprendizagem. Após as reflexões sobre a função humanizadora da educação (PÉREZ GÓMEZ, 1998) e da diferença entre conteúdos conceituais, procedimentais e atitudinais (PERRENOUD, 2013), passou a compreender que as metodologias transmissivas, no máximo, permitem uma aprendizagem limitada dos conteúdos conceituais. Como a escola exige que o aluno demonstre muitas habilidades de natureza procedimental nas avaliações, não é aceitável responsabilizar unicamente o aluno nos casos de fracasso nem atribuir todos os méritos ao professor em caso de sucesso, se tais saberes não forem objeto de ações pedagógicas sistemáticas.

O sexto problema ou mito - Os alunos aprendem mais com atividades lúdicas? - está diretamente ligado ao anterior e diz respeito à ideia bastante difundida de que é preciso fazer o aluno aprender brincando, ou seja, de maneira lúdica. A aluna responsável por discuti-lo admitiu também defender essa perspectiva até se dar conta, no processo de reflexão sobre a tipologia de conteúdos, que nem todos, dentre os quais muitos procedimentais, são passiveis de abordagem pela via da ludicidade.

O sétimo problema ou mito - A repetência melhora o desempenho dos estudantes? - foi, talvez, o mais problemático dentre os selecionados para o seminário, porque se referia ao dispositivo pedagógico/institucional que define, de maneira objetiva, o sucesso ou fracasso escolar: a avaliação. As discussões sobre a desigualdade na educação, desde a teoria da reprodução, concebiam o fracasso escolar como a falta de aprendizagem dos estudantes em relação aos conhecimentos e competências previstos no programa de curso de determinado período da escolarização. Com as críticas crescentes ao sistema escolar, foram incrementadas políticas de combate à reprovação que priorizaram os aspectos administrativos e burocráticos da gestão escolar sobre os aspectos ligados à formação e ao desenvolvimento profissional dos professores que tivessem como objetivo qualificá-los para a implementação 
de pedagogias diferenciadas. Como a aprovação não é, necessariamente, sinônimo de aprendizagem, o combate à reprovação tornou-se mais importante que o combate ao fracasso.

A aluna responsável por discutir esse problema mostrou-se favorável à reprovação, não por acreditar que ela necessariamente melhora o desempenho do estudante no ano seguinte, mas por entender que as escolas públicas optaram por mascarar o problema do fracasso escolar através da aprovação automática. Segundo ela, a proposta bem-intencionada da progressão continuada (ALMEIDA, 2017) foi utilizada equivocadamente para escamotear a prática de aprovação automática, sem as devidas garantias de aprendizagem. Diante disso, argumentou que, uma vez sabendo que o aluno será aprovado independente de seu nível de aprendizagem, o professor avalia qualquer tentativa de esforço no sentido de

O seminário

como

instrumento de avaliação processual e prática reflexiva na formação inicial de professores um trabalho pedagógico mais qualificado como inútil. Após essas considerações, minha intervenção se deu através da seguinte questão: nesse contexto, como fica o professor diante de sua responsabilidade moral e social no combate a essa "política perversa" de mascaramento da exclusão, sobretudo, dos mais pobres? Todos os alunos se posicionaram diante dessa pergunta, mas não chegamos a um consenso. Essa é uma das grandes questões que cada um terá de enfrentar no exercício profissional.

Após o encerramento das apresentações, iniciamos uma avaliação sobre todo o processo de produção do seminário em todas as suas etapas. Os estudantes não apenas reiteraram o discurso sobre a mudança de suas crenças quanto aos temas de suas respectivas apresentações, mas também ressaltaram a importância das apresentações dos colegas para auxiliar em suas reflexões sobre os demais temas. Com exceção do estudante que desistiu do curso, todos relataram mudanças em suas crenças acerca dos temas abordados. Nesse momento, explicitei que essa revisão das próprias crenças era o objetivo principal do seminário, que, para isso, teve organização redefinida no contexto de uma perspectiva de formação reflexiva do professor.

\section{Considerações finais}

Com a experiência relatada neste trabalho, tive o objetivo de apresentar reflexões que pudessem contribuir para a formação inicial de professores no contexto da epistemologia da prática, um paradigma eminentemente reflexivo, que exige estratégias pedagógicas e avaliativas coerentes com seus pressupostos. $\mathrm{O}$ modelo de seminário utili- 
Marcos Bispo dos Santos

zado mostrou-se adequado para dar conta do objetivo de promover uma formação centrada na prática reflexiva ao mesmo tempo em que constituiu importante estratégia pedagógica de avaliação processual e formativa. Como estratégia pedagógica, sua distribuição estrutural caracterizou-se pela ruptura com o modelo tecnicista de formação profissional, marcado, dentre outros fatores, pela concepção aplicacionista da relação teoria-prática, pela fragmentação do conhecimento, pela primazia da teoria sobre a prática, pela desconsideração das crenças e saberes dos futuros profissionais, pela concepção do ensino como transmissão e da aprendizagem como memorização e pela ênfase na avaliação classificatória.

Como instrumento de avaliação formativa, o modelo de seminário utilizado permitiu a inscrição dos sujeitos, com suas crenças e representações, no processo de reflexão e busca de racionalidade para as próprias convicções. Nesse sentido, permitiu que os futuros professores se dessem conta de sua responsabilidade moral com o saber, condição sine qua non para bem desempenhar seu papel social de combater as desigualdades sociais. Por outro lado, a avaliação do desenvolvimento da competência reflexiva demonstrou que ela não tem como fim conduzir os estudantes a verdades definitivas e generalizáveis. As discussões sobre os temas, problemas ou mitos relativos à educação que foram selecionados para o seminário demonstraram que o saber sobre a prática não conduz automaticamente a uma modificação dela, sendo, portanto, condição necessária, mas não suficiente para a transformação das práticas inspiradas em concepções equivocadas.

A estratégia de não revelar antecipadamente todos os critérios de avaliação que seriam utilizados, apesar de contrariar as teses de alguns autores que defendem a avaliação como um processo comunicativo e de negociação (HADJI, 2001), revelou-se, no contexto da prática formativa, um procedimento que permitiu reforçar a importância de se conhecer os sujeitos e suas representações sobre si mesmo e sobre a realidade antes das tomadas de decisão acerca da escolha das estratégias. Embora a autorregulação da aprendizagem seja uma meta da avaliação formativa, é importante não desconsiderar o fato de que, até o desenvolvimento da autonomia dos alunos, é preciso que o professor utilize estratégias adequadas de regulação para permitir tal desenvolvimento, uma vez que não é possível desenvolver a autonomia nem através da constante imposição de regras nem sem o recurso a nenhuma delas. 
Assim, ao deixar "ocultos" aos alunos dois critérios de avaliação - um voltado para a submissão das próprias crenças a exigências de racionalidade e outro, para a iniciativa de investir na ampliação O seminário do conhecimento através da leitura dos textos complementares - tinha como intenção permitir que agissem de maneira autônoma antes de tentar qualquer intervenção para ajustar suas ações. Quanto ao primeiro critério, apenas dois alunos permaneceram com as convicções que já tinham antes do trabalho com o seminário. Atribuí tal situação ao fato de não terem participado de maneira adequada das atividades desenvolvidas nas etapas preliminares à apresentação, mas não é possível afirmar categoricamente que essa foi a causa. 0 trabalho com crenças e representações deve ser acompanhado do reconhecimento de que nem sempre as pessoas estão dispostas a como instrumento de avaliação processual e prática reflexiva na formação inicial de professores abandonar as ideias em que acreditam. Quanto ao segundo critério, apenas três alunos demonstraram, durante as apresentações, terem lido pelo menos o texto complementar que fazia referência explícita a seus respectivos temas.

A avaliação dos alunos sobre a proposta desenvolvida evidenciou seus efeitos no processo de reflexão sobre as próprias crenças. Todos reconheceram a importância de submeter as próprias representações a exigências de racionalidade, sob o risco de continuar reproduzindo ideias ou mitos prejudiciais à compreensão do papel social do professor e, consequentemente, à formação dos estudantes da educação básica.

\section{REFERÊNCIAS}

ALMEIDA, F. J. Progressão continuada não é reprovação automática. Nova Escola. São Paulo, 01 de dez. 2010. Disponível em: <https:// novaescola.org.br/conteudo/287/progressao-continuada-nao-aprovacao-automatica>. Acesso em 17 de mai. 2017.

ALTET, M. As competências do professor profissional: entre conhecimentos, esquemas de ação e adaptação, saber analisar. In: PAQUAY, L.; PERRENOUD, P.; ALTET, M. CHARLIER, E. (Org.). Formando professores profissionais: quais estratégias? Quais competências? 2. ed. Trad. Fátima Murad; Eunice Gruman. Porto Alegre: Artmed, 2001, p. 23-35. 
BOUDON, R. A sociologia como ciência. Trad. Francisco Morás. Petrópolis, RJ: Vozes, 2016.

BOURDIEU, P.; PASSERON, J. C. A reprodução: elementos para uma teoria do sistema de ensino. 3. Ed. Trad. Reynaldo Bairão. Petrópolis: Vozes, 2010.

CHARLOT, B. Relação com o saber, formação dos professores e globalização: questões para a educação hoje. Trad. Sandra Loguercio. Porto Alegre: Artmed, 2007.

Marcos Bispo dos Santos

FERNANDES, E. 15 mitos da educação. Nova Escola. São Paulo, 01 de mar. 2011. Disponível em <https://novaescola.org.br/conteudo/1339/15-mitos-da-educacao>. Acesso em: 12 de mar. 2017.

GIL, A. C. Didática do ensino superior. São Paulo: Atlas, (2011).

GIMENO SACRISTÁN, J.; PÉREZ GÓMEZ, A. I. Compreender e transformar o ensino. 4. ed. Trad.: Ernani F. da Fonseca Rosa. Porto Alegre: Artmed, 1998.

HADJI. Ch. (1997). Avaliação desmistificada. Trad. Patrícia C. Ramos. Porto Alegre: Artmed, 2001.

LAHIRE, B. Sucesso escolar em meios populares: as razões do improvável. Trad. Ramon Américo Vasques; Sonia Goldfeder. São Paulo: Editora Ática, 2008.

LÉVY, P. As tecnologias da Inteligência: o futuro do pensamento na era da informática. Trad. Carlos Irineu da Costa. São Paulo. Editora 34, 2004.

LUCKESI, C. C. Avaliação da aprendizagem: componente do ato pedagógico. São Paulo: Cortez, 2011.

PACHECO, J. Para educador português, não se aprende nada em uma aula: entrevista. Folha de São Paulo. São Paulo, 06 de ser. 2016. Disponível em: <http://www1.folha.uol.com.br/educacao/2016/09/1810551- para-educador-portugues-modelo-escolar-do-sec-19-produz-ignorancia. shtml>. Acesso em: 18 de mai. 2017. 
PÉREZ GÓMEZ, A. I. As funções sociais da escola: da reprodução à reconstrução crítica do conhecimento e da experiência. In: GIMENO SACRISTÁN, J.; PÉREZ GÓMEZ, A. I. Compreender e transformar o ensino. 4. ed. Trad.: Ernani F. da Fonseca Rosa. Porto Alegre: Artmed, 1998, p. 13-26.

O seminário como instrumento de avaliação processual PERRENOUD, P. Avaliação: da excelência à regulação das aprendizagens - entre duas lógicas. Trad. Patrícia Chittoni Ramos. Porto Alegre: Artmed, 1999.

e prática reflexiva na formação inicial de

A prática reflexiva no ofício de professor: profissionalização e razão pedagógica. Trad. Cláudia Schilling. Porto Alegre: professores Artmed, 2002.

Desenvolver competências ou ensinar saberes? A escola que prepara para a vida. Trad. Laura Solange Pereira. Porto Alegre: Penso, 2013.

SCHÖN, D. A. Educando o Profissional Reflexivo: um novo design para o ensino e a aprendizagem. Trad. Roberto Cataldo Costa. Porto Alegre: Artmed, 2000.

SEVERINO, A. J. Metodologia do trabalho científico. 22. Ed. São Paulo: Cortez, 2002.

TARDIF, M; GAUTHIER, C. O professor como "ator racional": que racionalidade, que saber, que julgamento? In: PAQUAY, L.; PERRENOUD, P.; ALTET, M. CHARLIER, E. (Org.). Formando professores profissionais: quais estratégias? Quais competências? 2. ed. Trad. Fátima Murad; Eunice Gruman. Porto Alegre: Artmed, 2001, p. 185-210.

TARDIF, M. Saberes docentes e formação profissional. 12. ed. Trad.: Francisco Pereira. Petrópolis, RJ: Vozes, 2011.

VAN HAECHT, A. Sociologia da educação: a escola posta à prova. 3. Ed. Trad. Sandra Loguercio. Porto Alegre: Artmed, 2008. 
ZABALA, A.; ARNAU, L. O objetivo da educação por competências é o pleno desenvolvimento da pessoa. In: ZABALA, A. et al. Didática geral. Trad. Carlos Henrique Lucas Lima. Porto Alegre: Penso, 2016, p. 1-24.

Marcos Bispo

dos Santos

348 